\title{
Habercilikte Hizdan Kaynaklanan Etik Sorunların Ortaya Çıkmasının Engellenmesi veya Azaltılmasında Yeni Medya Kullanımının Olası Etkileri
}

DOI: 10.26466/opus.913122

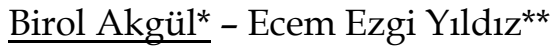 \\ * Doç. Dr, Çanakkale Onsekiz Mart Üni., İletişim Fakültesi, Çanakkale/Türkiye \\ E-Posta: birolakgul@hotmail.com \\ ORCID: 0000-0002-0701-0928 \\ ** Yl Öğrencisi, Çanakkale Onsekiz Mart Üni, Lisansüstü Eğt. Ens., Çanakkale/Türkiye \\ E-Posta: ecemezgiii@gmail.com \\ ORCID: $\underline{0000-0001-6051-1291}$
}

$\ddot{O} z$

Geleneksel medya ve yeni medya arasında başta teknoloji kullanımı olmak üzere birçok fark mevcuttur. Bu farklar medya sektörü içerisindeki rekabet olgusunu şekillendirmekle birlikte, bireyin ilgisini medya araçları arasinda pay etmesi sürecinde de büyük etki sahibidir. Bahsedilecek olan hız olgusu, belirli bir zaman çizelgesi içerisinde yapılması gereken görevlerin gerektirdiği hızı kapsamamaktadır. $B u$ çalışmada, hız olgusunun interaktif oluşumlarda, bireylerin şahsi istekleri doğrultusunda haberciliğe sağladığı katılımlarda ya da yoğun olarak yeni medyanın getirilerinden olan anlık iletimlerde oluşturduğu etik sorunlar ele alınmıştır. Hiz olgusunun oluşturduğu ya da oluşmasına katkı sağladığı etik sorunlar, haberlerin bireyleri yanıltmasına, dilin bozulmasına, bilgi kirliliğine ve bununla birlikte basının itibarsızlaşmasına yol açmaktadır. Bu sebeple hızın basına ve bireye să̆ladığı avantajlardan vazgeçilmeden, hizdan kaynaklanan sorunların önüne geçilmelidir. Bu sayede basının itibarı ve güvenilirliği korunacak ayrıca bireylerin doğru habere kolay ulaşımı sağlanacaktır. Çalışma üçana bölümden oluşmaktadır. İlk bölümde medya ve habercilikte hız kavramlarmın tanımı yapılmıştır. İkinci bölümde habercilikte hızdan kaynaklanan etik sorunlar ele alınmıştır. Üçüncü bölümde ise, habercilikte hızdan kaynaklanan etik sorunların ortaya çımasının engellenmesi ya da azaltılması konusunda yeni medyanın olası kullanımı tartışılmıştır. Çalışmada literatür taraması, örnek olay incelemesi ve kurgulama yöntemleri bir arada kullanılmıştır.

Anahtar Kelimeler: Habercilik, Haber Toplamada Hiz Unsuru, Etik Sorunlar. 


\title{
Possible Effects of New Media Use in Preventing or Reducing the Emergence of Ethical Problems Arising from Speed in Journalism
}

\begin{abstract}
There are many differences between traditional media and new media, especially the use of technology. These differences shape the phenomenon of competition within the media sector, but also have a great impact on the process of sharing the individual's interest among media tools. The speed phenomenon to be mentioned does not cover the speed required by tasks to be performed within a given timeline. In this study, the ethical problems posed by the speed phenomenon in interactive formations, the participation of individuals in reporting according to their personal wishes, or the instantaneous transmissions that are the result of the new media are discussed. The ethical problems created or contributed to the formation of the speed phenomenon lead to news misleading individuals, distortion of language, information pollution and, with it, to discredit the press. For this reason, without giving up the advantages of speed to the press and the individual, problems arising from speed should be avoided. In this way, the reputation and credibility of the press will be protected and individuals will be provided with easy access to accurate news. The work consists of three main parts. In the first section, the concepts of speed in media and journalism are defined. In the second part, ethical issues arising from speed in journalism are addressed. In the third chapter, the possible use of new media in preventing or reducing the emergence of ethical problems arising from speed in journalism is discussed. In the study, literature review, case study and editing methods were used together.
\end{abstract}

Keywords: Reporting, Speed in Reporting, Ethical Problems 


\section{Giriş}

Hizdan kaynaklanan etik sorunlar, geleneksel medyaya nazaran yeni medyada bireylerin karşısına çıkmaktadır. Bunun sebebi, hız olgusunun yeni medyada daha büyük bir yere ve öneme sahip olmasıdır. Geleneksel medyanın yapısı, interaktif yayıncllık ve yurttaş haberciliğinden daha uzaktır. Bu durum geleneksel medya ve hız arasındaki ilişkiyi sınırlı tutmaktadır. Geleneksel medya araçlarından dergiler ya da gazeteler belirli bir sürede belirli gündemler üzerine oluşturulmaktadır. Oluşturulduğu süre içerisinde yaşanmış mevcut gündemi aktaran yazılı basın kanalları, basım ve dağıtım sürecinden sonraki zaman diliminde yaşanan olayların aktarılmasından sorumlu tutulmamaktadır. Böylece ilgili olayların yazımı için yeterli araştırma ve doğrulama sürelerine sahip olmaktadırlar. Buna rağmen yeterince olgunlaşmadan iletilen ya da doğrulanmadan servis edilen haberler ile karşılaşılması mümkündür. Böyle bir süreçten yararlanamayan yeni medya, anlık ve hızlı haber iletimini gerçekleştirmekle yükümlüdür. Aksi halde ilgi kaybı ve ilgi ile doğru orantılı bir biçimde maddi kazanç düşüşü yaşayacaktir.

Yeni medyanın tercih edilmesinde etkisi bulunan ana başlıklardan biri hız olgusudur. Televizyonda ya da radyolarda son dakika haberi niteliğinde olmadığı için yayınlanmayan ya da geç yayınlanan, gazete ya da dergilerde yer alması için yeni sayıları beklemek mecburiyeti taşıyan haberlere, yeni medyada ulaşmak mümkündür. Yeni medya, çoğu zaman belli bir bültenden bağımsızdır ve anlık haber iletimi sağlamaktadır. Detay haber, hızlı iletim ve etkileşim ögelerini içinde bulunduran yeni medya, hız olgusu sayesinde geleneksel medyayı geride bırakmıştır. Hız olgusu, yeni medyanın yükselişine sebep olmakla birlikte aynı zamanda yeni medyaya zarar verebilmektedir.

Geleneksel medya ve yeni medyada hızdan kaynaklanan etik sorunlar öncelikle belirlenmeli, sonrasında incelenmeli ve sorumlu kişiler tarafından sorunların çözümüne yönelik çalışmalar yapılmalıdır. Aksi halde medyanın itibarsızlaşması, güvenilirliğinin zedelenmesinin önüne geçilemeyecek ve bireyler oluşan bilgi karmaşası içerisinde yanıltıcı haberlere sıkça maruz kalacaklardir. 


\section{Medya ve Hız Kavramlarının Yapısı ve Kapsamı}

Bu bölümde çalışma konusunun kavramsal çerçevesi açiklanmıştır. Öncelikle medya kavramının tanımı ve yapısal incelemesi yapılmıştır. Ardından hız olgusu, geleneksel medya ve yeni medya bağlamında karşılaştırmalı olarak ele alınmıştır.

\section{Medya}

"Medya denildiğinde, klasik yayın organları olan gazete, televizyon ve radyo akıllara gelmektedir. İletişim teknolojilerinin sayısallaşması yeni yazılımlar ve uygulamalar ile hayatımıza yeni medya, sosyal medya, dijital medya, internet medyası gibi birtakım kavramlar girmiştir" (Adıgüzel, 2016, s.28). Medyanın asıl amacı, bireyin mikro çevresinde, makro çevresinde ve dünyada olup bitenleri bilmesini olanaklı kllmak; yani olup bitenler hakkında kişinin kendi fikirlerine ve kararlarına temel hazırlayarak fikir üretme özgürlüğüne ulaşmasını sağlamaktır. Geniş anlamda medyanın asıl işi dünya gündeminde yaşanan olayları ya da durumları bireye aktarmaktır (Usta, 2009, s.474).

Medyanın halka dünyadan sesler vermesinin yanı sıra halkın sesi olması ayrıca mevcut durumda bireysel ve toplumsal iletişimi sağlayan en büyük araç haline gelmesi sebebiyle etik kurallar çerçevesinde hareket etmesi çok büyük önem arz etmektedir. Medya, halkın her kesimine hitap etme ve halkı bilgilendirme misyonunu taşıması sebebiyle bilgilerini öncelikle doğru sonrasında güncel tutmakla yükümlüdür (Ceylan, 2012, s.46-47).

Medya eğlence, sosyalleşme, boş zamanı değerlendirme gibi birçok amaç için kullanılsa da medyanın birincil görevi haber vermektir. İnsanlık tarihinin başlangıcından bu yana bireyler duman, çizim, ses gibi birçok yöntem ile haberleşmeye ya da bilgi aktarımı sağlamaya çalışmışlardır. Az sayıda insanın yaşadığı kabile toplumlarında bu yöntemler işe yarıyor olsa da yaşadığımız küresel toplumlarda bu iletişim yöntemlerinin kullanılması olanaksız, birebir iletişim ise yetersizdir. Bireylerin fizyolojik sınırları, seslerini ve düşüncelerini insanlığın tümüne aktarmasına engel olmaktadır. Bu sebeple medya her durum, koşul, olay, haber ve düşünceyi bireylerden toplumlara ya da dünya gündeminden bireye aktarmak için tek seçenektir. Böylesine önemli bir yere sahip olan medyanın kötüye kullanımını önlemek, 
birey ya da toplum yaşamına zarar vermesini engellemek ve kültürleri tahrip etmeden devam etmesini sağlamak için bazı kurallara ihtiyacı vardır. Toplumsal düzenin sağlanmasına ve bireyin doğru davranışına yönelik olan etik kuralların, medyada da uygulanması tartısılmaz bir gerekliliktir. Medya ve onun asıl amacı olan haberleşmede, etik açıdan aksaklık oluşturabilecek problemlerden biri de bireylerin isteği ve kullanımı dolayısıyla oluşan hızdan kaynaklanan etik sorunlardır.

Anlamı itibariyle çabukluğu temsil eden hız, birçok iktisadi ve sosyal alanda kendine yer bulmaktadır. Psikolojik olarak da bireylerin bir avantaj olarak algıladığı ve yaşamlarına dahil etmek istediği hız olgusu, herhangi bir kişiyi, durumu, sektörü ya da firmayı tercih etme sebepleri arasında gösterilebilir. Teknolojinin yoğun olarak kullanıldığı mevcut durumda bireyler, istediğine istediği anda ulaşma arzusu taşımaktadır. Bu arzu elbette haber alma isteği için de geçerliliğini korumaktadır. Bireyler için ailesinden ve yakın çevresinden haber almanın yanı sıra içerisinde yaşadığı muhitin, vilayetin ya da toplumun durumuna, çalıştığı firmanın, sektörün ya da ülkenin geleceğine dair gündemi öğrenme isteği olağandır. Özellikle müdahale etme gücünün bulunduğu durumları bilmek birey için gerekli sosyal bir ihtiyaçtır. Mevcut durum incelendiğinde hıza sahip olmak bazı sosyal ve ticari kimlikler için güce sahip olmak anlamını da taşımaktadır.

Hıza sahip olma isteği şiddetine göre derecelendirildiğinde, bu isteği üst seviyede taşıyan bireyler aceleci olarak nitelendirilir ve bu durum psikiyatride davranış bozuklukları arasında değerlendirilir. Mevcut durumda yoğun toplum ve dünya gündeminden haber alamamak kişilerde gerginliğe sebep olmaktadır. Sabırsızlık, konuşma ve davranışta acelecilik gösteren zaman sıkışıklığı duygusu taşıyan, daha hızlı davranma ve sınırlı zamana en çok işi sığdırma dürtüsüyle hareket eden kişiler A tipi kişilikler olarak adlandırılmaktadır (Scully, 1990, ss.238-239; Arslanoğlu, 2002:158). Yoğun teknolojinin kullanıldığı mevcut dönemde de bireyler dereceleri değişmekle birlikte A tipi kişilikler ile aynı semptomları göstermektedir ve psikiyatrik olan bu sorun sadece bireyleri değil sektörleri de etkilemektedir. Habercilik sektörü toplumun genelinde görülen hizlı elde etme isteğini karşılamak için içerikleri ve haberleri hızlı servis etmekte, bu durum ise bazı etik sorunların oluşmasına yol açmaktadır. 


\section{Geleneksel Medya ve Yeni Medyada Hiz Olgusu}

Kitle iletişiminin gelişmesine öncülük eden ilk geleneksel medya araçlarından olan gazeteler, 17. yüzylldan itibaren gündemi takip etmek için kullanılan önemli kaynaklardandır. Dergiler ise gazetelerin sağladıkları genel gündem takibi siteminden farklı olarak, belli bir konuya ya da ilgi alanına yönelik içerikler sağlamaktadır. Radyolar müdahale edilebilir yayınları ile haber iletiminde gazete ve dergilere göre çok daha hızlıdır. Televizyon ise geleneksel medya içerisinde, sunduğu çeşitlilik ve kullandığı yoğun teknoloji sayesinde varlığını en etkin sürdüren medya aracıdır.

Gazete ve dergiler, hiz olgusundan hem olumlu hem olumsuz etkilenmektedir. TÜIK 2016 verilerine göre gazete ve dergilerin yıllık tirajları, 2015 yılına göre \%20 azalmıştır çünkü bireyler hızlı ulaşabilecekleri kaynaklardan haber almayı daha avantajlı ve kolay bulmaktadırlar. Gazeteler ve dergilerin basılacağı zaman aralıkları bellidir ve anlık haber akışı sağlayamazlar bu sebeple bireylerin büyük bir kısmı haber takibini internet üzerinden yapmaktadırlar. Teknoloji günlük rutine fazlasıyla entegre olmuş bir vaziyettedir ve bireyler istedikleri bilgilere internet üzerinden ulaşabilmektedir. Buna rağmen 2016 yılında yayımlanan gazete ve dergilerin yıllık toplam tirajı $1 \mathrm{mi}-$ lyar 705 milyon 225 bin olarak açıklanmıştır ve yayımlanan gazetelerin $\% 86,9^{\prime}$ u siyasi/haber/güncel içerikli yayın yapmıştır. Bu verilere göre bireyler, yaşamlarını etkileyecek haberleri çoğunlukla yeni medya aracilığıyla öğrenseler bile yeni medyanın güvenilirliği bireyler açısından henüz bir netlik kazanmamıştır. Bu sebeple bireyler haberleri teyit etmek için geleneksel medya araçlarından yararlanmaya devam etmektedirler (TÜİK, 2017).

Televizyon, habere hızlı ulaşmak kıstas alındığında gazete, dergi ve radyolardan çok daha etkilidir lakin internet ile rekabeti mevcut durumda olanaksızdır. Gelirini birey ilgisinden sağlamakta olan televizyon kanalları, toplumun acilen bilgilendirilmesini gerektirecek önemde bir hadise olmadıkça öncesinde uygulanması planlanmış yayın akışlarına sadık kalmak mecburiyetindedirler. Bu sebeple ekonomi, siyaset, spor ya da sanat ile ilgili toplumu ilgilendiren lakin acil olmayan haberlere en hızlı ulaşım elbette internet aracılığıyla sağlanacaktır. Habere hızlı ulaşma durumu birey açısından değerlendirildiğinde ise bireyin kendisi, yakın çevresi, yaşadığı yer ya da bireysel ilgi alanlarını içeren detay haberleri bulabileceği en hızlı medya aracı yine internettir. 
TÜİK verilerine göre 2017 yılı Nisan ayında hanelerin \%80,7'si evden İnternete erişim imkanına sahiptir (TÜİK, 2017). Bu verilerin ışığında, internet kullanımının hızla yayıldığı ve internet erişimi sayesinde ulaşılabilen uygulama ve sitelerin kullanımlarının arttığı söylenebilir. Bireylerin hızlı haber alma ya da gündemi takip etme istekleri, sosyal medya kullanımı, e-devlet sistemi, alışveriş siteleri, sağlık kurumlarının online randevu ve sonuç sistemleri gibi birçok farklı alanda kullandıkları internet bireylere başta hız olmak üzere kolaylık ve seçenek gibi imkanlar da sunmaktadır. Kanalların televizyon yayınları ile aynı anda internette canlı yayın yapması, dizi ve programlara internet üzerinden istenilen anda kolay ulaşım sağlanması, radyoların internet üzerinden yaptıkları eş zamanlı yayınlar, gazete ve dergilerin mobil uygulamaları ve siteleri de interneti her şeyi bulabilecekleri bir medya aracı olarak daha cazip kılmaktadır.

\section{Habercilikte Hizdan Kaynaklanan Etik Sorunlar}

Medyanın asli görevi haber vermektir. Bu sebeple medyada etik sorunlardan arındırılması en zaruri alan haberciliktir. Buradan hareketle habercilikte etik açıdan önemli sorunlar oluşturabilecek konulardan biri olan hız olgusunun incelenmesi gerekmektedir. Habercilikte hizdan kaynaklanan sorunların incelenmesi ve çözümüne yönelik öneri sunulması için geniş bir çalışma alanına ihtiyaç vardır. Hızdan kaynaklanan sorunlar dilin yanlış kullanımına yol açabildiği gibi yalan haber oluşumuna da sebep olabilmektedir. Yeni medyada yayınlanmış haberlerin doğruluğunun bireyler tarafindan geleneksel medya ile teyit edilmesi hızdan kaynaklanan bir problemdir. Ancak geleneksel medyada yaşanan hız kaynaklı hataların düzeltilmesi için de yine hızı dolayısıyla yeni medyaya başvurulmaktadır. Bu sebeple hız olgusu kimi zaman hayat kurtarabileceği gibi kimi zaman da hayati hatalara sebep olabilir. Bu sebeple hız olgusunun sağladığı avantajlar en verimli biçimde kullanılırken, hızdan kaynaklanan hataların önüne geçilmesi medyanın itibarına değer katacaktır. Ayn zamanda medyanın güvenilirliğinin net çizgiler ile sabitleştirilmesine temel hazırlayacaktır. Bu bölümde habercilikte hızdan kaynaklanan temel sorunlar, dört ana başlıkta incelenmektedir. 


\section{Haberin Olgunlaşmadan Servis Edilmesi}

Horkheimer geleneksel kuram için asıl isteğin 'bütün yapısal parçaların kurallara uygun bir biçimde ve çelişiksiz olarak birbirine bağlanması olduğunu' savunmuştur (Slater, 1989, s.54; Küçükcan, 2002, s.262). Bu düşünce haber ya da içerik oluşturmaya uyarlandığında, hızdan kaynaklanan sorunların haberin bütününü olumsuz bir biçimde etkilediği sonucuna ulaşılmaktadır.

Hızdan kaynaklanan sorunları birer birer ele almamız gerekirse, ilk sırada haberin ya da içeriğin olgunlaşmadan, doğrulanmadan ya da etik değerlere uygunluğuna kanaat getirilmeden servis edilmesi olmalıdır. Habere ilgi duyması muhtemel kitleyi kendi kanal ya da sitesinde toplamak amacı ile yapılan hatalardır. Habere duyulan ilgi reklam getirecektir ve reklamların artması gelirin artması anlamına gelmektedir. Bu sebeple bir haberi ya da içeriği ilk yayınlayan yer olmak, bireylerin ilgisini tek bir yerde toplamak anlamina gelmektedir. Bu sebeple haberler ya da içerikler, doğrulanmadan ya da henüz mühim detaylar anlaşılmadan servis edilebilmektedir. Yeni medyada haberin güncellenebilir olmasının sağladığı güven, eksik ya da yanlış haberlerin oluşturulmasında rol oynamaktadır. Geleneksel medyada haberler yayınlandıktan sonra yalnızca tekzip ile düzeltilmektedir ve yayının belirli sıklıklarla yapılması sebebiyle mevcut durumda ilk olma telaşı, geleneksel medyada yaygın bir durum değildir. Lakin öncesinde yapılmış, etik olmayan ve insan psikolojisine etkileri düşünülmeden yapılmış canlı yayınlar geleneksel medyada ilgili sorun için yerinde bir örnektir. Her iki durumda da basının güvenilirliği sarsılmaktadır ve medya itibarsızlaşmaktadır.

Basın Konseyi'nin yayınladığı Basın Meslek İlkeleri 6. Madde 'Soruşturulması gazetecilik olanakları içinde bulunan haberler, soruşturulmaksızın veya doğruluğuna emin olmaksızın yayınlanamaz.' demektedir. Bu sebeple tüm medya kuruluşları için hızdan önce doğruluğun ve güvenilirliğin gelmesi gerekmektedir (Basın Konseyi, http://basinkonseyi.org.tr/basin-meslek-ilkeleri/ 13.05.2018 tarihinde erişildi).

Örnek olay incelemesinden yararlanıldığında, Ruhdan Uzun'un İletişim Etiği Sorunlar ve Sorumluluklar adlı kitabından konu ile alakalı üçörnek olay mevcuttur. İlk örnek Susurluk Olayı incelendiğinde, olay gerçekleştikten sonra olay ile ilgili pek çok bilgi süzülmeden ya da doğruluğu ispatlanmadan servis edildiği için haberler bağlantıları ortaya çıkarmaktan çok olayın daha da karmaşık bir hal almasını sağlamıştır. Olayın algılanması güçleştiği için, 
aşırı bilgi yüklemesi ya da bilgi kirliliği ile birlikte neyin doğru neyin yanlış olduğu anlaşılamaz hale gelmiş ve haberlerin bireyleri aydınlatma amacı sağlanamamıştır. İkinci örnek, TGRT'de yayınlanan 'Taksim'de Patlama' haberidir. 26 Temmuz 2005'te TGRT ekrandan 'Taksim' de patlama oldu. Çok sayıda yaralı var' altyazısı geçti ve dünya gündeminin de karışık olduğu bir zamanda bu haber huzla hem kanallar arasında hem de diğer kitle iletişim araçlarında yayıldı, insanlar paniğe kapıldı ve sonunda haberin asılsız olduğu ortaya çıtı. Üçüncü örnek ise BBC'nin 2004 yılı Eylül ayında Rusya'da yaşanan bir okul baskınını canlı olarak yayınlamasıdır. Çok sayıda ölü ve yaralının canlı yayınlanması tepki toplamıştır ve BBC bu olaydan sonra hassas konuların canlı yayınlarının gecikmeli yapılmasını ilkeye bağlamıştır (Uzun, 2007: 179-180).

Yeni medyada yakın zamanda gerçekleşmiş bir örnek olay incelendiğinde ise, haberleri ilk duyuran olma kaygısının haberlerin doğrulatılmadan halka servis edilmesi gibi yanlış sonuçlara yol açtı̆̆ gözlemlenmektedir. 2018'in Şubat ayında Hürriyet Gazetesinin internet sayfasında yayınladığı haberde, Genelkurmay Başkanlığı tarafından yazılmış olduğu iddia edilen açıklama metni kaynak gösterilerek askerlik sürelerinin uzatıldığı duyurulmuştu. Genelkurmay Başkanlığı Basın ve Halkla İlişkiler Daire Başkanlığı haberi kısa süre içerisinde kesin bir şekilde yalanladı lakin geçen kısa sürede, haber doğrulatılmadan birçok haber sitesi ve paylaşım sayfasında yayınlanmıştı. Toplumda yoğun etkileşime sebep olan haber, gerçek açıklanana kadar etkisini artarak sürdürdü (NTV, 2018).

\section{Bilgi Kirliliği}

İkinci sorun bilgi kirliliğidir. Uygulamaların ve sitelerin içerik paylaşımında sağladığı kolaylıklar ile haberler özellikle internet ortamında hızlı yayılma özelliğine sahiptir. Bireylerin içerikte şahsi görüşlerine uyan kısımları anında birebir olarak paylaşabilmesi ya da içeriğin tümünün kaynak göstermeksizin yayılması gibi unsurlar sebebiyle bilgi kirliliği artmaktadır. Anahtar kelimeler üzerinden yapılan aramalarda birçok kaynağa ulaşılmakta ve doğru bilginin ayıklanması sancılı bir süreç olmaktadır. Bireylerin özgürce düşünebilmesi ve paylaşabilmesi olumlu bir durumdur lakin her düşüncenin bilinçsizce ve bilimsel herhangi bir temele dayandırılmaksızın farklı kişiler ve kaynaklar aracılığıyla sakıncalı davranışlardan arındırılmadan paylaşılması 
olumsuz sonuçlar doğurabilmektedir. İlgili konu ile bağlantısı olmayan içeriklerin, ufak çağrışımlar ile konu ile bağlantılı gösterilmesi ve bu tip içeriklerin hızla yayılması da etik bir sorun teşkil etmektedir.

Sosyal medya uygulamalarında bulunan yorum özelliği bilgi kirliliğine verilebilecek örneklerdendir. Yapılan haber paylaşımlarında, mühim ana temaların yanı sıra kişilerin takıldığı ufak detayları uzun yorumlar şeklinde gönderilere ekleyebilmesi okuyucunun dikkatini dağıtmakta ve konudan sapma yaşamasına sebep olmaktadır. Hakaret barındıran yorumların kaldırılması dahi zaman alırken, konu ile güçlü bağlantısı olmayan yorumların ayıklanması süreci büyük zaman kaybına yol açmakta ve okur bilgi kirliliğinden olumsuz etkilenmektedir. Hızla eklenebilen yorumlar, haberi itibarsızlaştırabilmektedir.

Yine internet üzerinden kolaylıkla yapılabilen paylaşımlar, haberleşmeyi bazı durumlarda olumsuz etkilemektedir. Kolay ve hızlı bir biçimde içerik ya da haber üretebilme hakkına sahip olan bireyler, doğruluğu kesin kanallardan ispatlanmamış haberlere yönelik içerikler ya da sansasyon oluşturmak için gerçek dışı haberler oluşturabilmektedir. Çoğunlukla siyasi, sportif ya da sosyal faaliyetler üzerine oluşturulan bu haberlerin kaynağı araştırılmaksızın paylaşımı, gündemde yanlış bilgilerin hızla yayılmasına ve toplum bilincinin yanlış yönlendirilmesine sebep olmaktadır.

Geleneksel medya üzerine bir örnek olay incelemesi olarak, medya kullanımının bu denli yoğun olmadığ 1963 tarihinde uğradığı silahlı saldırıda yaşamını yitiren Amerika Birleşik Devletleri 35. Başkanı John F. Kennedy'nin öldürülmesi ile ilgili milyonlarca belge olduğu açıklanmıştır (CNN TÜRK, 2017: https://www.cnnturk.com/dunya/kennedy-suikasti-ileilgili-yeni-belgeler-aciklandi).

Toplumların internet ya da sosyal medya kullanmadığı zamanlarda, bu denli belge ve bilginin aktarılması yine hızdan kaynaklanan etik problemler ile açıklanabilir. Mevcut medya araçlarının, ilk bilgiyi ya da daha çok bilgiyi en hızlı ve en çok aktarma endişesi, bulunan her detayın ve söylenen her cümlenin kapsamlı araştırılma yapılmaksızın servis edilmesine ve çok büyük oranda bilgi kirliliğine yol açmıştır. 


\section{Telif Sorunu}

Haberlerin ya da içeriklerin kaynak gösterilmeksizin hızlı paylaşımı, eser sahibinin hak iddia etmesini zorlaştırmakla birlikte eser sahibinin hak ettiği değeri görmesine engel olacaktır.

Özellikle sosyal medya uygulamalarında beğeni alma potansiyeli taşıyan bilgi, haber ya da görsellerin ikinci kişiler tarafından birinci kişiymişçesine aktarılması sıklıkla yaşanan bir durumdur. Bu durum, bireylerin paylaştıkları içerikler üzerinde hak iddia etmesini güçleştirmekte ve bireyin içeriğin getirdiği avantajlardan yararlanmasını önlemektedir.

T.C. Kültür ve Turizm Bakanlığı Telif Hakları Genel Müdürlüğü'nün belirttiği ‘Telif Hakkının doğması için tescile gerek yoktur. Fikir ve sanat eserleri üzerindeki haklar eserin üretilmesiyle birlikte doğar' özelliğinin görmezden gelinmesi ve 1948 Tarihli Birleşmiş Milletler Genel Kurulu'nda kabul edilen İnsan Hakları Evrensel Bildirgesi'nin 27. Maddesinde bulunan bireyin ‘Herkesin sahibi bulunduğu (yarattı̆̆) her türlü bilim, edebiyat veya sanat eserinden doğan manevi ve maddi yararlarını korunmasını isteme hakkı vardır.' cümlesindeki hakkının çiğnenmesi de internet üzerinde hızdan kaynaklanan bir diğer problemdir (Telif Hakları Genel Müdürlüğü, http://www.telifhaklari.gov.tr/Telif-Hakki-Nedir 13.05.2018 tarihinde erişildi).

\section{Dilin Yanlış Kullanımı}

Dilin doğru kullanılmaması ve hataların olağanlaşması olarak açıklanabilir. Yorum etkileşiminin bulunduğu haber uygulamalarında günlük yaşamdan kazanılan bir alışkanlık olan anında cevap alma isteği ve haber sitelerinin haberi ilk yayınlayan yer olma telaşı dilin doğru kullanımı konusunda bir özensizliğe sebep olmaktadır. Hızlı yayınlanan haberler ve hızlı yapılan yorumlar, günlük yaşamda dile yerleşmiş ama kullanımının yanlış olduğu bilinen kelimelerin, cümlelerin ya da kalıpların haberde kullanılmasına yol açabilir. Cinsiyetçi tabirler, yazım hataları, kısaltmalar ve yabancı kökenli kelimeler gibi dilin daralmasına ya da yanlış kullanılmasına sebep olabilecek durumların önüne geçmek için, kamu yararı adına acil yayın gerektirmeyen durumlarda hızdan önce dilin doğru kullanımına dikkat edilmelidir. Dildeki değişim davranışı da değiştirir ve dilin gerilemesi kültürün gerilemesidir. 


\section{Habercilikte Hızdan Kaynaklanan Etik Sorunların Ortaya Çıkmasının En- gellenmesi Veya Azaltılması Konusunda Yeni Medya Kullanımının Olası Etkileri}

Bilgi ve iletişim teknolojilerindeki gelişmeler, yeni medya adı altında yeni habercilik türlerinin ortaya çıkmasını sağlamıştır. Bu durum, yeni medya etiğinin geleneksel medya etiği ile yorumlanmasını zorlaştırmıştır. Yeni medya araçlarıyla yapılan haberciliğin etik açıdan yorumlanmasında, yeni bir bakış açısına ihtiyaç duyulmaktadır. Günümüzde geleneksel medyaya göre daha hızlı haber içeriği üretilmektedir. Gazeteci kimliği olsun ya da olmasın, herkes haber içeriği üretebilmektedir. Bazen editöryal süreçlerden dahi geçmeyen haber içerikleri, medyada bilgi kirliliğine yol açmaktadır. Dolayısıyla, yeni medya etiğinin eskisinden farklı bir anlayışla değerlendirilmesi gerektiği düşünülmektedir.

Yeni medyanın içerisinde bulunduğu bilgi bolluğu içerisinde, kaynağı teyit edilmiş ve haber değeri taşıyan gelişmelerin saptanması oldukça önem kazanmıştır. Toplumun her kesiminin içerik üretmesi ve haber paylaşımının internet kanalıyla yapılabilmesi, haberlerin dağıtımını hızlandırmıştır. Çevrimiçi haber platformlarında hızlı bilgi akışı devam ederken aynı zamanda topluma doğru bilginin aktarılmasına çalışılmaktadır. Mevcut durumda medya etiği ilkeleri zaman zaman göz ardı edilebilmektedir. Bunun sonucunda, doğruluğu teyit edilmeyen bilgi yığınları oluşmaktadır. Günümüzde çevrimiçi araçlarla çalışan medya sektöründe temel amaç, haberin mümkün olan en çok kişiye ulaştırılmasıdır. Haberin içeriği, kaynağ ve doğruluğundan ziyade, haberin ne kadar çok kişiye ulaştığı önem kazanmıştır. Dolayısıyla dijital medya araçlarının kullanıldığı ortamlarda çalışan gazetecilerin, haberin kaynağını ve doğruluğunu teyit etmeye zamanı kalmamaktadır. Bu durumda, gazetecilerin internet ortamında paylaşılan haber içeriklerinin gerçeği yansıtmama ihtimalini göz önüne alarak hareket etmesi uygun olacaktır. Kaynağından teyit edilmeden içerik paylaşımı yapılmaması, olası siyasi kriz ve hak mağduriyetlerinin önüne geçecektir.

Bilişim teknolojilerinin hızla gelişmesinden kaynaklanan bilgi yığınının oluşturacağı olası bilgi kirliliğinin, yine aynı teknoloji kullanılarak azaltılabileceği öngörülmektedir. Yalnızca internet ortamındaki arama motorları kullanılarak dahi, çoğu bilgi kaynağına ulaşılabilmektedir. Yeni medya araçlarının etkin bir şekilde kullanılması ve medya okuryazarlığının 
geliştirilmesi, haberlerin doğruluğunun tespiti açısından kritik öneme sahiptir. Haberin doğruluğu saptanırken, öncelikle haber kaynağı esaslı bir biçimde incelenmeli, mümkünse birden fazla kanaldan kaynağa ulaşılmaya çalışılmalıdır. Varsa habere ilişkin görsel, işitsel ve yazılı içerikler temin edilerek karşılaştırmalı analiz yapılmalıdır. Ayrıca, haber kaynakları analiz edilirken gerekli izinler alınarak erişim ve paylaşım yapılmalıdır. Habere konu olan kişi ya da kişilerle ilişkin detaylar, özel hayatın gizliliği ilkesi göz önüne alınarak araştırılmalı ve paylaşılmalıdır.

\section{Sonuç ve Öneriler}

Hız, hem yayını takip eden bireyler hem de yayın yapan medya kuruluşları için önemli ve fazlasıyla avantaj barındıran bir olgudur. Hızın habercilikte doğru şekilde kullanılması hem bireylerin yaşamını kolaylaştıracak, hem de basına olan güven ve bağlılığın artmasını sağlayacaktır. Doğru kullanılmaması durumda hız, bizzat yanlış kullanım sağlayan kuruluşlara, içinde bulunduğu medya sektörüne ve gündemi ilgili kuruluştan takip eden bireye zarar verebilmektedir. Çoğunlukla birey kaynaklı olan habercilikte, hızdan kaynaklanan etik sorunların önüne geçilmesi mümkündür. Medya mensuplarının konuya yönelik eğitimi ve internet üzerinde üretilen içeriklerin bilinçli paylaşımına yönelik bazı önlemlerin de sorunların çözüm sürecine katkı sağlayacağı düşünülmektedir. 


\title{
EXTENDED ABSTRACT
}

\section{Possible Effects of New Media Use in Preventing or Reducing the Emergence of Ethical Problems Arising from Speed in Journalism}

\author{
Birol Akgül - Ezgi Ecem Yıldız \\ Çanakkale Onsekiz Mart University
}

It is of great importance that the media act within the framework of ethical rules, as it is the voice of the people, as well as giving voices to the public from the world, and has become the biggest tool that provides individual and social communication in the current situation. Although the media is used for many purposes such as entertainment, socialization, and leisure time, the primary task of the media is to provide fast and accurate news.

The new media, which includes detailed news, fast transmission and interaction elements, has left the traditional media behind thanks to the speed phenomenon. Ethical problems arising from speed are faced by individuals in new media compared to traditional media. The phenomenon of speed causes the rise of new media, but it can also harm new media. This is because the phenomenon of speed has a greater place and importance in new media. The main problems arising from speed in journalism; It is examined in four groups as serving the news before it is mature, information pollution, copyright problem and misuse of language.

In the first place among the problems caused by speed; It is possible to say that there is a problem of 'news being served prematurely'. It is very common for news or content to be served before it is matured, verified or judged to be in compliance with ethical values. Conscious mistakes are made in order to gather the possible audience on their own channel or site so that they are interested in the news. Interest in the news will bring advertising, and increased advertising means increased revenue. For this reason, being the first place to publish a news or content means to gather the attention of individuals in one place. For this reason, news or content can be served without being verified or without understanding important details yet. 
The second problem is information pollution. With the convenience provided by applications and sites in content sharing, news has the feature of spreading rapidly, especially in the internet environment. Information pollution is increasing due to factors such as the fact that individuals can instantly share parts of the content that fit their personal views, or that the entire content is disseminated without citing the source. Many sources are reached in searches made through keywords, and extracting the right information is a painful process. It is also an ethical problem that the contents that are not related to the relevant subject are shown in connection with the subject with small connotations and the rapid spread of such contents.

The third problem is the copyright issue. Rapid sharing of news or content without citing the source will make it difficult for the owner of the work to claim rights, but will prevent the owner of the work from seeing the value he deserves. Especially in social media applications, it is a frequent situation that information, news or images that have the potential to be liked are transferred by second people as if they were first person. This situation makes it difficult for individuals to claim rights on the content they share and prevents the individual from taking advantage of the content.

The fourth problem is the problem of language misuse. It can be explained as the incorrect use of the language and the normalization of errors. The desire to get instant answers, which is a habit acquired from daily life in news applications where there is comment interaction, and the rush of news sites to be the first place to publish the news cause carelessness in the correct use of language. Quickly broadcast news and quick comments may lead to the use of words, phrases or phrases that are embedded in the language in daily life but whose usage is known to be incorrect.

Speed is an important and highly advantageous phenomenon for both individuals following the broadcast and broadcasting media organizations. The correct use of speed in journalism will both facilitate the lives of individuals and increase trust and loyalty to the press. If it is not used correctly, speed can harm the organizations that make wrong use, the media sector in which they are involved, and the individual who follows the agenda from the relevant organization. In journalism, which 
is mostly based on individuals, it is possible to avoid ethical problems arising from speed. It is thought that some measures for the education of the media members and the conscious sharing of the content produced on the internet will contribute to the solution process of the problems.

In this study, the ethical problems posed by the speed phenomenon in interactive formations, the participation of individuals in reporting according to their personal wishes, or the instantaneous transmissions that are the result of the new media are discussed. The ethical problems created or contributed to the formation of the speed phenomenon lead to news misleading individuals, distortion of language, information pollution and, with it, to discredit the press. For this reason, without giving up the advantages of speed to the press and the individual, problems arising from speed should be avoided. In this way, the reputation and credibility of the press will be protected and individuals will be provided with easy access to accurate news.

The work consists of three main parts. In the first section, the concepts of speed in media and journalism are defined. In the second part, ethical issues arising from speed in journalism are addressed. In the third chapter, the possible use of new media in preventing or reducing the emergence of ethical problems arising from speed in journalism is discussed. In the study, descriptive research method and data analysis method were used together.

\section{Kaynakça / References}

Adıgüzel, Y. (2016). Medya İlişkileri. Eskişehir: T.C. Anadolu Üniversitesi Yayını,No:3602.https://webcache.googleusercontent.com/search?q=cache:3hoRsxfdmUYJ:https://www.academia.edu/35516653/Gelneksel_Medya_ile_\%25C4\%25B0li\%25C5\%2

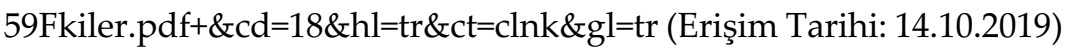
Arslanoğlu, K. (2002). Psikiyatri El Kitabı. İstanbul: Adam Yayınları. Basın Konseyi. (2018). Basin Meslek Illkeleri. 5 13, 2018 tarihinde Basın Konseyi: http://basinkonseyi.org.tr/basin-meslek-ilkeleri/ adresinden alındı.

Ceylan, Y. (2012). Toplumsal Değerler ve Medya Etiği. Dicle Üniversitesi Sosyal Bilimler Enstitüsü Dergisi, 4(7), 45-58. 
CNN TÜRK. $(2017,114)$. Kennedy suikasti ile ilgili yeni belgeler açıklandı. 5,16, 2018 tarihinde CNN TÜRK Haber: https://www.cnnturk.com/dunya/kennedy-suikasti-ile-ilgili yenibelgeler- aciklandi adresinden alındı.

Küçükcan, U. (2002). Frankfurt okulu ve kitle kültürü çalışmaları. Kurgu Dergisi, 2(3), 257-269.

NTV. (2018, 22). TSK'dan "askerlik uzadı" iddiasıyla ilgili açıklama. 6, 7, 2018 tarihinde NTV: https://www.ntv.com.tr/turkiye/tskdan-askerlikuzadi-iddiasiyla-ilgili-aciklama-askerlik-uzadimi,Ezkm8YfKlEwAWgd4 kmLeQ adresinden alınd 1

Scully, J. H. (1990). Psikiyatri. (E. Bayraktar, ve E. Özmen, Çev.) İzmir: Ege Üniversitesi Basımevi.

Slater, P. (1989). Frankfurt okulu: Kökeni ve önemi. (A. Özden, Çev.) İstanbul: BFS Yayınları.

Telif Hakları Genel Müdürlügü. (2018). Telif hakkı nedir. 5, 13, 2018 tarihinde Telif Hakları Genel Müdürlügü: http://www.telifhaklari.gov.tr/TelifHakki-Nedir adresinden alındı.

TÜİK. (2017, 818). Hanehalkı bilişim teknolojileri kullanım araştırması, 2017.5,13,2018 tarihinde Türkiye İstatistik Kurumu: http://www.tuik.gov.tr/PreHaberBultenleri.do?id=24862 adresinden alındi.

TÜIK. (2017, 726). Yazılı medya istatistikleri, 2016. 5 13, 2018 tarihinde Türkiye İstatistik Kurumu: http://www.tuik.gov.tr/PreHaberBultenleri.do?id=24673 adresinden alındı.

Usta, A. (2009). Medyatik eylemlerin sosyo-psikolojik etkisi. Medya ve Etik Sempozyumu Kitabı. Elazığ.

Uzun, R. (2007). İletişim etiğgi sorunlar ve sorumluluklar. Ankara: Gazi Üniversitesi İletişim Fakültesi Basımevi.

\section{Kaynakça Bilgisi / Citation Information}

Akgül, B. ve Yıldız, E. E. (2021). Habercilikte hızdan kaynaklanan etik sorunların ortaya çıkmasının engellenmesi veya azaltılmasında yeni medya kullanıminin olası etkileri. OPUS-Uluslararası Toplum Araştırmaları Dergisi, 17(38), 5569-5585. DOI: 10.26466/opus.913122 